\title{
Anopheles gambiae s.I (Diptera: Culicidae) seasonal abundance, abdominal status and parity rates in Metema-Armachiho lowland, Northwest Ethiopia
}

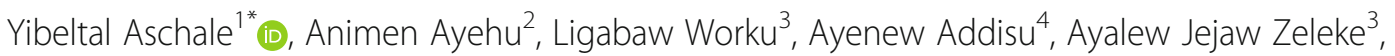
Abebe Genetu Bayih ${ }^{4}$ and Wossenseged Lemma ${ }^{3}$

\begin{abstract}
Background: Malaria is a life threating vector borne disease caused by different Plasmodium parasites. Metema and Armachiho are two of the top five malaria endemic areas among the districts of Amhara region in Ethiopia. Transmission pattern is seasonal and migrant laborers who visit these areas for employment in mechanized agriculture are highly affected. The aim of this study was to investigate seasonal abundance, abdominal status and parity rate of An.gambiae s.l in Metema-Armachiho lowlands, Northwest Ethiopia.

Method: A 1 year longitudinal entomological study was conducted in Metema-Armachiho lowlands from June 2016May 2017. Mosquitoes were collected using CDC-light traps in indoor and outdoor sites for four consecutive days in each month. A total of eight standard battery operated CDC-light traps were used to collect mosquitoes. Female mosquitoes were classed as unfed, fed or gravid under a dissecting microscope. The ovaries of all unfed An.gambiae s.l mosquitoes were examined for evidence of parity. Data were entered and analyzed using SPSS-20 software. Chi-square test was applied to show significant difference between variables. $P$-value $<0.05$ was taken as statistically significant.

Results: Of the total 1253 mosquitoes collected, 713 (552 female, 161 male) were culex and 540 (501 female, 39 male) were An.gambiae s.l. About 50.9\% were collected in June-August 2016, 21.7\% in September-November 2016, 12.0\% in December 2016-February 2017 and 15.4\% in March to May 2017. Of the total, 57.2 and 42.8\% of the An.gambiae s.l were collected from indoor and outdoor sites respectively. Of the total females collected, $76.8 \%$ were unfed; of which $69.4 \%$ were parous. Significantly higher number of female An.gambiae s.I were collected in indoor and there was significant difference in abdominal status of An.gambiae s.I mosquitoes collected in different season $(P<0.05)$.

Conclusions: Highest number of An.gambiae s.I was observed from June-August followed by September-November. The parity rate of An.gambiae s.l was high and there was significant difference in abdominal status of An.gambiae s.l collected in different season.
\end{abstract}

Keywords: Seasonal abundance, An.gambiae s.l, Abdominal status, Parity

* Correspondence: yibea33@gmail.com

'Department of Medical Parasitology, College of Health Sciences, Debre Markos University, P.O. Box: 269, Debre Markos, Ethiopia

Full list of author information is available at the end of the article

(c) The Author(s). 2020 Open Access This article is licensed under a Creative Commons Attribution 4.0 International License, which permits use, sharing, adaptation, distribution and reproduction in any medium or format, as long as you give appropriate credit to the original author(s) and the source, provide a link to the Creative Commons licence, and indicate if changes were made. The images or other third party material in this article are included in the article's Creative Commons licence, unless indicated otherwise in a credit line to the material. If material is not included in the article's Creative Commons licence and your intended use is not permitted by statutory regulation or exceeds the permitted use, you will need to obtain permission directly from the copyright holder. To view a copy of this licence, visit http://creativecommons.org/licenses/by/4.0/ The Creative Commons Public Domain Dedication waiver (http://creativecommons.org/publicdomain/zero/1.0/) applies to the data made available in this article, unless otherwise stated in a credit line to the data. 


\section{Background}

Malaria burden is high in poor and malnourished populations [1]. Labor migrants who travel to endemic areas, under five children and pregnant women are high risk groups for malaria infection [2-4]. Malaria transmission in Ethiopia is seasonal and affected by rainfall and altitude patterns [5-7]. Transmission period varies from a few weeks prior to the main rainy season (April-June) to more than a month following main rainy season (September-December) which coincides with the major harvesting and planting seasons $[5,8,9]$. Thus, it has a severe impact on Ethiopia's economy by cutting down productivity capacity [10].

Family Culicidae consists of two principal lineages that are recognized as subfamilies, the Anophelinae and Culicinae [11]. Of the 465 properly identified Anopheles mosquito species worldwide, 70 have the ability to transmit malaria parasites in humans [12]. An. arabiensis, which belongs to An.gambiae s.l, is the primary vector of malaria parasite in Ethiopia. However, An. pharoensis, An. nili and $A n$. funestus are secondary malaria vectors [13-15]. A large decrease of the important endophilic-endophagic malaria vectors (An. gambiae sensu stricto and An. funestus) and persistence of the more exophilic-exophagic species ( $A n$. arabiensis) have been observed now a days $[15,16]$.

Regular indoor residual spraying (IRS) and long lasting insecticide treated nets (LLITNs) are currently vector control intervention strategies in Metema and Armachiho [5, 7]. Environmental management is also key intervention measure applied to control malaria in the study areas [13, 17]. Modification of the environment has great effect on breeding of mosquitoes. It affects mosquito abundance by altering both quality and quantity of breeding sites [18].

Effectiveness of malaria prevention with LLITNs and IRS is inadequate due to emergence of insecticide resistance, outdoor and early evening/morning biting mosquitoes. New vector control tools are required and their efficiency should be improved. Therefore, studying $A n$. gambiae s.l mosquito abundance, abdominal status and parity rate in Metema and Armachiho lowlands, which are among the hot spot areas of malaria in Ethiopia, is essential to design and apply complementary vector control tools that target outdoor and early morning/evening bitters to scale up malaria prevention and to reduce the burden of malaria in the study area.

\section{Methods}

\section{Study area}

The study was conducted in Metema-Armachiho lowlands, Northwest Ethiopia, considered as single survey domain, in three randomly selected villages; Kumer $\left(13^{\circ} 00^{\prime} \mathrm{N} / 36^{\circ} 15^{\prime} \mathrm{E}\right)$, Selam ber $\left(13^{\circ} 45^{\prime} \mathrm{N} / 36^{\circ} 24^{\prime} \mathrm{E}\right)$ and Abderafi $\left(13^{\circ} 41^{\prime} \mathrm{N} / 36^{\circ} 28^{\prime} \mathrm{E}\right)$. The altitude of Metema and West Armachiho Districts is 685 and $667 \mathrm{~m}$ above sea level respectively. The minimum annual temperature for both districts ranges from $22{ }^{\circ} \mathrm{C}$ to $28^{\circ} \mathrm{C}$. The daytime temperature is very high during March to May (reaches up to $43^{\circ} \mathrm{C}$ ). These districts are hyper-endemic malarious areas and the weather condition is appropriate for mosquito vector breeding [19].

\section{Study design and period}

A 1 year longitudinal entomological study was conducted from June 2016 to May 2017 in MetemaArmachiho lowlands, Northwest Ethiopia. Entomological surveys were conducted in three villages (four houses from each village) using eight CDC-light traps in indoor and outdoor.

\section{Mosquito collection and processing methods Mosquito collections}

Mosquitoes were collected daily according to the WHO standard protocol using standard battery operated CDClight traps set overnight $(18,00-06: 00 \mathrm{~h})[20,21]$. A total of 12 houses, four houses from each village, were selected for the survey. Collection was made from 12 houses for four consecutive days in each month. A total of eight CDC-light traps were used to collect mosquitoes indoor and outdoor at $1-2 \mathrm{~km}$ distance from potential breeding sites. They were hanged $1.5 \mathrm{~m}$ above the ground. Indoor collection was performed in bedroom and outdoor collection was performed in verandas.

\section{Anopheles gambiae s.I mosquito processing}

All collected adult An. gambiae s.l mosquitoes were first anesthetized with ethyl ether for $30 \mathrm{~min}$ in an anesthetizing chamber. The sex and species of all collected mosquitoes were identified using standard keys [22-24] and labeled according to date and site of collection. Female mosquitoes were classed as unfed, fed or gravid under a dissecting microscope.

\section{Dissection and examination of ovaries}

The ovaries of all unfed An.gambiae s.l mosquitoes were examined for evidence of parity by observing whether they contained eggs or whether the tracheolar skeins surrounding the ovaries were coiled or uncoiled [20-22].

\section{Data analysis and interpretation}

The data was appropriately coded, entered, checked for completeness and analyzed using SPSS 20 software. Descriptive statistics, frequency and cross tabulations were used. The findings were presented in text, table and graph. Chi-square test was used for statistical analysis to show significant difference between variables. $P$-value< 0.05 was taken as statistically significant. 
Table 1 Number of An.gambiae s.l collected indoor and outdoor between June 2016 and May 2017 in Metema-West Armachiho lowlands, Northwest Ethiopia $(N=540)$

\begin{tabular}{|c|c|c|c|c|c|}
\hline \multirow{2}{*}{$\begin{array}{l}\text { Site of } \\
\text { collection }\end{array}$} & \multicolumn{2}{|l|}{ Sex } & \multirow[t]{2}{*}{ Total } & \multirow{2}{*}{$\begin{array}{l}x^{2} \\
\text { Value }\end{array}$} & \multirow{2}{*}{$\begin{array}{l}\text { P- } \\
\text { Value }\end{array}$} \\
\hline & $\begin{array}{l}\text { Male An. } \\
\text { gambiae s.l }\end{array}$ & $\begin{array}{l}\text { Female } \\
\text { An.gambiae s.l }\end{array}$ & & & \\
\hline Indoor & $8(20.5)$ & $301(60.1)$ & $\begin{array}{l}309 \\
(57.2)\end{array}$ & 23.1 & $<0.05$ \\
\hline Outdoor & 31 (79.5) & $200(39.9)$ & $\begin{array}{l}231 \\
(42.8)\end{array}$ & & \\
\hline Total & $39(7.2)$ & 501 (92.8) & $\begin{array}{l}540 \\
(100)\end{array}$ & & \\
\hline
\end{tabular}

\section{Result}

During the survey a total of 1253 (713 culex, 540 An. gambiae s.l) mosquitoes were collected from 192 CDClight traps in both indoor and outdoor sites. Of the total An.gambiae s.l samples, 92.8\% (95\% CI: 90.5-94.8) were female, and $57.2 \%$ (95\% CI: $52.9-61.6)$ and $42.8 \%$ (95\% CI: 38.4-47.1) were from indoor and outdoor sites respectively. Significantly higher number of female An.gambiae s.l mosquitoes were collected in indoor $(\mathrm{x} 2=23.1, P<0.05)($ Table 1$)$.

\section{Seasonal abundance of An. gambiae s.I mosquitoes}

About 50.9\% were collected in June-August 2016, 21.7\% in September-November 2016, 12.0\% in December 2016February 2017 and 15.4\% in March to May 2017. There was significant difference in number of An.gambiae s.l mosquitoes collected and season $\left(x_{2}=41.9, P<0.05\right)$. In Abderafi, highest number of An.gambiae s.l mosquitoes were collected in September-November 2016 and lowest number of An.gambiae s.l mosquitoes were collected in December 2016-February 2017. In Selam Ber, highest number of An.gambiae s.l mosquitoes were collected in June-August 2016 and lowest number of An.gambiae s.l mosquitoes were collected in March-May 2017. Significantly highest number of An.gambiae s.l mosquitoes were collected in June to August in Kumer and Selam ber, whereas, significantly highest number of An.gambiae s.l mosquitoes were collected in September-November in Abderafi $\left(\chi^{2}=135.9, P<0.05\right)($ Table 2$)$.
Indoor-outdoor distribution of mosquitoes across villages In Kumer, approximately equal number of mosquitoes were collected in indoor and outdoor. In Abderafi, higher number of mosquitoes were collected in indoor than outdoor whereas, in Selam Ber there is a slight increase in outdoor. Significantly highest number (235) of mosquitoes were collected from Kumer $\left(\chi_{2}=32.9 ; P<0.05\right)$ (Fig. 1$)$.

\section{Abdominal status of An.gambiae s.l mosquitoes}

The abdomen of 501 female An.gambiae s.l mosquitoes was examined to determine abdominal status. Of which, 76.8\% (95\% CI: $73.1-80.4$ ), 14.4\% (95\% CI: 11.4-17.4), 8.8\% (95\% CI: 6.4-11.2) were found unfed, fed and gravid, respectively. There was significant difference in abdominal status of An.gambiae s.l mosquitoes collected in different season. Significantly higher number of unfed An.gambiae s.l mosquitoes were captured from December to February $(P<0.05)$ (Table 3$)$.

\section{Parity rate of An.gambiae s.I mosquitoes}

The ovaries of 385 unfed An.gambiae s.l mosquitoes were examined to determine parous rate. Of which, 69.4\% (95\% CI: 64.9-73.9) An.gambiae s.l mosquitoes were found parous and 30.6\% (95\% CI: 26.1-35.1) were found nulliparous. There was no significant difference in parity rate of An.gambiae s.l mosquitoes collected in different season $\left(\chi^{2}=0.062, P=0.99\right)($ Table 4$)$.

\section{Discussion}

This entomological study was the first time study carried out in Northwest Ethiopia to assess An. gambiae s.l. seasonal abundance, abdominal status and parity rate. Molecular analysis of An.gambiae s.l mosquitoes revealed that $A n$. arabiensis is the only vector member of the complex in malaria endemic areas of Ethiopia [14, 25, 26]. Larval ecology indicates that An. gambiae s.l larvae develop in freshwater habitats that are small, temporary, clean and sun-exposed. The larva may breed in any available water, even in dirty and polluted habitats [27].

In this study, the highest number of An.gambiae s.l. were collected during rainy season of which $57.2 \%$ were from indoor sites and $42.8 \%$ were from outdoor sites

Table 2 Seasonal abundance of An.gambiae s.I mosquitoes in different villages collected between June 2016 and May 2017 in Metema-Armachiho Lowlands $(N=540)$

\begin{tabular}{|c|c|c|c|c|c|c|}
\hline \multirow[t]{2}{*}{ Season } & \multicolumn{3}{|l|}{ Villages } & \multirow{2}{*}{$\begin{array}{l}\text { Total } n \\
(\%)\end{array}$} & \multirow{2}{*}{$\begin{array}{l}x^{2} \\
\text { value }\end{array}$} & \multirow{2}{*}{$\begin{array}{l}P- \\
\text { Value }\end{array}$} \\
\hline & Kumer n (\%) & Abderafi $n(\%)$ & Selam Ber $n(\%)$ & & & \\
\hline Jun-Aug 2016 & $145(61.7)$ & $45(24.7)$ & $85(69.1)$ & $275(50.9)$ & & \\
\hline Sep-Nov 2016 & $15(6.4)$ & $88(48.4)$ & $14(11.4)$ & $117(21.7)$ & 135.9 & $<0.05^{*}$ \\
\hline Dec 2016-Feb 2017 & $29(12.3)$ & $23(12.6)$ & $13(10.6)$ & $65(12.0)$ & & \\
\hline Mar-May 2017 & 46 (19.6) & $26(14.3)$ & $11(8.9)$ & $83(15.4)$ & & \\
\hline Total & $235(100)$ & $182(100)$ & $123(100)$ & $540(100)$ & & \\
\hline
\end{tabular}

*Statistically significant 


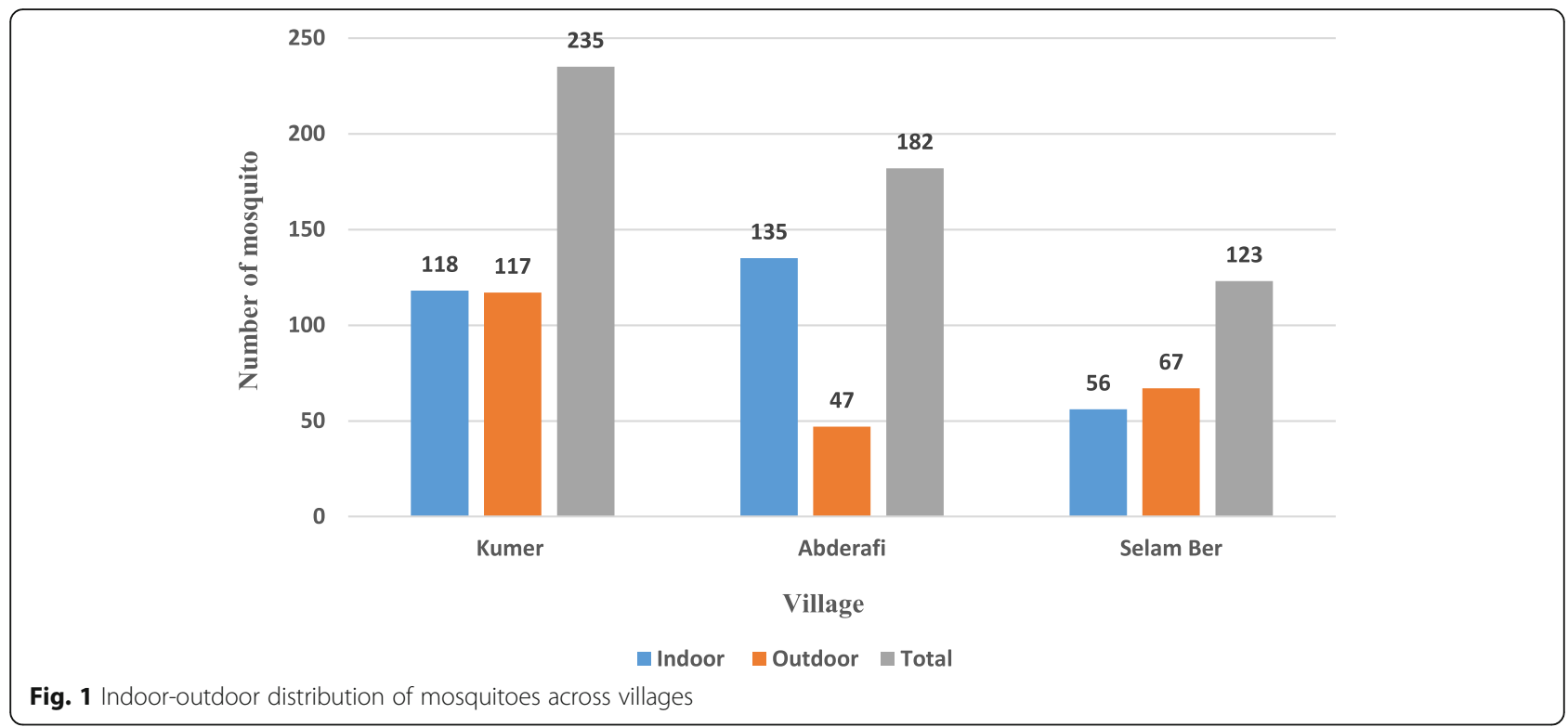

indicating the outdoor host seeking and resting behavior of An.gambiae s.l. Significantly higher number of male An.gambiae s.l were collected in outdoor and significantly higher number of female An. gambiae s.l were collected in indoor $(P<0.05)$. This indicates that only female mosquitoes seek blood for the development of their egg and male normally can survive by feeding on nectar juice. This is comparable with a previous study conducted in Sille, South Ethiopia which demonstrated that 54.2 and $45.8 \%$ of An.gambiae s.l were collected from indoor and outdoor sites respectively [28]. On the other hand, this finding is somewhat different from a previous study conducted in other part of Ethiopia, in which $44.4 \%$ of An.gambiae s.l were captured from indoor and $55.6 \%$ were collected from outdoor [29]. The reason for different proportions of indoor or outdoor biting might be due to human behaviour. In the study area (Metema and Armachiho district) migrant laborers often work outdoor and sleep in the open field exposing themselves for outdoor biters. This affects host seeking behaviors of An.gambiae s.l.

Of all female An.gambiae s.l mosquitoes examined for abdominal status, $76.8 \%$ were found unfed, $14.4 \%$ were found fed and, $8.8 \%$ were found gravid. The gravid An.gambiae s.l mosquitoes collected outdoor were either coming out to seek resting habitat or they were initially unfed indicating their outdoor resting and biting (partial exophillic-exophagic) behavior. There was significant difference in abdominal status of An.gambiae s.l mosquitoes collected in different seasons $(P<0.05)$.

Of all unfed female An.gambiae s.l mosquitoes examined, $69.4 \%$ were found parous and $30.6 \%$ were nulliparous. There was no significant difference in parity rate of An.gambiae s.l mosquitoes collected in different seasons $(P>0.05)$. This finding is comparable with previous study conducted in Sille, South Ethiopia with an overall parous rate of $73.2 \%$ [28] and higher than a study conducted in East Wellega Zone, West Ethiopia with an

Table 3 Abdominal status of An.gambiae s.I mosquitoes collected between June 2016 and May 2017 in Metema-West Armachiho lowlands, Northwest Ethiopia $(N=501)$

\begin{tabular}{|c|c|c|c|c|c|c|}
\hline \multirow[t]{2}{*}{ Season } & \multicolumn{3}{|c|}{ Abdominal status } & \multirow{2}{*}{$\begin{array}{l}\text { Total } n \\
\text { (\%) }\end{array}$} & \multirow{2}{*}{$\begin{array}{l}X^{2} \\
\text { value }\end{array}$} & \multirow{2}{*}{$\begin{array}{l}P- \\
\text { Value }\end{array}$} \\
\hline & $\begin{array}{l}\text { Unfed } \\
n(\%)\end{array}$ & $\begin{array}{l}\text { Fed } \\
n(\%)\end{array}$ & Gravid $n(\%)$ & & & \\
\hline Jun-Aug 2016 & $197(72.4)$ & $49(18.0)$ & $26(9.6)$ & $272(100)$ & & \\
\hline Sep-Nov 2016 & $80(83.3)$ & $10(10.4)$ & $6(6.3)$ & $96(100)$ & 43.7 & $<0.05^{*}$ \\
\hline Dec 2016-Feb 2017 & $61(100)$ & $0(0)$ & $0(0)$ & $61(100)$ & & \\
\hline Mar-May 2017 & $47(65.3)$ & $13(18.0)$ & $12(16.7)$ & $72(100)$ & & \\
\hline Total & $385(76.8)$ & $72(14.4)$ & $44(8.8)$ & $501(100)$ & & \\
\hline
\end{tabular}

*Statistically significant 
Table 4 Parity rate of An.gambiae s.l mosquitoes collected between June 2016 and May 2017 in Metema-West Armachiho lowlands, Northwest Ethiopia $(N=385)$

\begin{tabular}{|c|c|c|c|c|c|}
\hline \multirow[t]{2}{*}{ Season } & \multicolumn{2}{|c|}{ Parity status } & \multirow{2}{*}{$\begin{array}{l}\text { Total } n \\
(\%)\end{array}$} & \multirow{2}{*}{$\begin{array}{l}x^{2} \\
\text { Value }\end{array}$} & \multirow{2}{*}{$\begin{array}{l}P \text { - } \\
\text { Value }\end{array}$} \\
\hline & $\begin{array}{l}\text { Parous } \\
n(\%)\end{array}$ & $\begin{array}{l}\text { Nulliparous } \\
n(\%)\end{array}$ & & & \\
\hline Jun-Aug 2016 & $137(69.5)$ & $60(30.5)$ & $197(100)$ & & \\
\hline Sep-Nov 2016 & $56(70)$ & $24(30)$ & $80(100)$ & 0.062 & 0.99 \\
\hline Dec 2016-Feb 2017 & $42(68.9)$ & $19(31.1)$ & $61(100)$ & & \\
\hline Mar-May 2017 & $32(68.0)$ & $15(32)$ & $47(100)$ & & \\
\hline Total & $267(69.4)$ & 118 (30.6) & 385 (100) & & \\
\hline
\end{tabular}

overall An. arabiensis parous rate of $45 \%$ [14]. The reason for this difference might be due to difference in mosquito sampling season, mosquito sampling duration and host availability.

\section{Conclusions}

An.gambiae s.l abundance was highest in June-August followed by September-November. The parity rate of An.gambiae s.l was high and there was significant difference in abdominal status of An.gambiae s.l collected in different season. Supplementary vector control tools like larval source management and use of vapor phase repellents are required to tackle outdoor or early biting. In addition, there should be active surveillance including asymptomatic carriers.

\section{Abbreviations}

IRS: Indoor Residual Spray; LLITNs: Long Lasting Insecticide Treated Nets; s.l: sensu lato

\section{Acknowledgements}

We would like to thank University of Gondar for funding this research. We are grateful to all volunteers who participated in collection of mosquitoes.

\section{Authors' contributions}

YA and WL conceived and designed the study. $A A^{2}, W L$, and $L W$ participated in data collection, laboratory analysis and interpretation. YA analyzed the data and wrote the first draft of the manuscript. $A G B, A J Z$ and $A A^{3}$ critically reviewed the manuscript. All authors approved the submitted version.

\section{Funding}

The research was funded by University of Gondar.

\section{Availability of data and materials}

The datasets used and/or analyzed during the current study are available from the corresponding author upon reasonable request.

\section{Ethics approval and consent to participate}

Ethical clearance was obtained from the ethical committee of School of Biomedical and Laboratory Sciences, University of Gondar. Permission was obtained from North Gondar Zone Health Department as well as from Metema and West Armachiho Woreda Health Offices. Informed written consent was obtained from all participants of mosquito collection.

\section{Consent for publication}

Not applicable in this section.

\section{Competing interests}

The authors declare that they have no competing interests.

\section{Author details}

'Department of Medical Parasitology, College of Health Sciences, Debre Markos University, P.O. Box: 269, Debre Markos, Ethiopia. ${ }^{2}$ Department of Medical Parasitology, College of Medicine and Health Sciences, Bahir Dar University, Bahir Dar, Ethiopia. ${ }^{3}$ Department of Medical Parasitology, School of Biomedical and Laboratory Sciences, College of Medicine and Health Sciences, University of Gondar, Gondar, Ethiopia. ${ }^{4}$ Director General,Armauer Hansen Research Institute (AHRI), Addis Ababa, Ethiopia.

Received: 1 April 2019 Accepted: 3 May 2020

Published online: 11 May 2020

\section{References}

1. World Health Organization. World malaria report 2017. Geneva: World Health Organization; 2018.

2. Martens P, Hall L. Malaria on the move: human population movement and malaria transmission. Emerg Infect Dis. 2000;6(2):103.

3. World Health Organization. World malaria report 2016. Geneva: WHO; 2016.

4. Rowe AK, Rowe SY, Snow RW, Korenromp EL, Schellenberg JRA, Stein C, Nahlen BL, Bryce J, Black RE, Steketee RW. The burden of malaria mortality among African children in the year 2000. Int J Epidemiol. 2006;35(3):691704.

5. Federal Democratic Republic of Ethiopia. National strategic plan for malaria prevention, control and elimination in Ethiopia, 2011-2015. Addis Ababa: $\mathrm{FMoH} ; 2015$.

6. Adhanom T, Deressa W, Witten H, Getachew A, Seboxa T. Malaria: in the epidemiology and ecology of health and disease in Ethiopia. 1st ed. Addis Ababa: Shama Books; 2006.

7. Peterson I, Borrell LN, El-Sadr W, Teklehaimanot A. Individual and household level factors associated with malaria incidence in a highland region of Ethiopia: a multilevel analysis. Am J Trop Med Hyg. 2009;80(1):103-11.

8. Jima D, Getachew A, Bilak H, Steketee RW, Emerson PM, Graves PM, Gebre T, Reithinger R, Hwang J. Malaria indicator survey 2007, Ethiopia: coverage and use of major malaria prevention and control interventions. Malar J. 2010;9(1):1.

9. Graves PM, Richards FO, Ngondi J, Emerson PM, Shargie EB, Endeshaw T, Ceccato P, Ejigsemahu Y, Mosher AW, Hailemariam A. Individual, household and environmental risk factors for malaria infection in Amhara, Oromia and SNNP regions of Ethiopia. Trans R Soc Trop Med Hyg. 2009;103(12):1211-20.

10. Federal Democratic Republic of Ethiopia Ministry of Health. Malaria: diagnosis and treatment guidelines for health workers in Ethiopia. Addis Ababa: FMoH; 2004

11. Mitchell A, Sperling FA, Hickey DA. Higher-level phylogeny of mosquitoes (Diptera: Culicidae): mtDNA data support a derived placement for Toxorhynchites. Insect Syst Evol. 2002;33(2):163-74.

12. Service M, Towson $\mathrm{H}$. The Anopheles vector in essential malariology. 4th ed. London: Edward Arnold; 2002.

13. Federal Democratic Republic of Ethiopia Ministry of Health. National malaria guidlines. Addis Ababa: FMoH; 2012.

14. Jaleta KT, Hill SR, Seyoum E, Balkew M, Gebre-Michael T, Ignell R, Tekie H. Agro-ecosystems impact malaria prevalence: large-scale irrigation drives vector population in western Ethiopia. Malar J. 2013;12(1):1.

15. Sinka ME, Bangs MJ, Manguin S, Coetzee M, Mbogo CM, Hemingway J, Patil AP, Temperley WH, Gething PW, Kabaria CW. The dominant Anopheles vectors of human malaria in Africa, Europe and the Middle East: occurrence data, distribution maps and bionomic précis. Parasit Vectors. 2010;3(1):1.

16. Durnez $\mathrm{L}$, Coosemans $\mathrm{M}$. Residual transmission of malaria: an old issue for new approaches. In: Anopheles mosquitoes - new insights into malaria vectors; 2013. p. 671-704.

17. Keiser J, Singer BH, Utzinger J. Reducing the burden of malaria in different eco-epidemiological settings with environmental management: a systematic review. Lancet Infect Dis. 2005;5(11):695-708.

18. Tandon N, Hati AK. Some recent malaria problems in the hill district of Eastern India. Memoirs School Entomol. 1978;6:117-212.

19. Ayalew D, Tesfaye K, Mamo G, Yitaferu B, Bayu W. Variability of rainfall and its current trend in Amhara region, Ethiopia. Afr J Agric Res. 2012;7(10): $1475-86$.

20. World Health Organization. Division of malaria and other parasitic diseases. In: Manual on practical entomology in malaria part II methods and techniques. Geneva: World Health Organization; 1975. 
21. Abeyasingha R, Yapabanadara A, Kusumawathie P, Perera D, Peiris B, Hewavitharane H, Harishchandra R. Guidelines for entomological surveillance of malaria vectors in Sri Lanka. Kurunegala: Anti-Malaria Campaign; 2009. p. 62-7.

22. World Health Organization. Malaria entomology and vector control (learner's guide). Geneva: WHO; 2003.

23. Gillies M, Coetzee M. A supplement to the Anophelinae of Africa South of the Sahara. Publ S Afr Inst Med Res. 1987;55:1-143.

24. Veronne G. Outline for the determination of malarial mosquitoes in Ethiopia. Part I. Adult female anophelines. Mosq News. 1962;22:37-49.

25. Balkew M, Ibrahim M, Koekemoer LL, Brooke BD, Engers H, Aseffa A, GebreMichael T, Elhassen I. Insecticide resistance in Anopheles arabiensis (Diptera: Culicidae) from villages in central, northern and south West Ethiopia and detection of kdr mutation. Parasit Vectors. 2010;3(1):40.

26. Fettene M, Olana D, Christian R, Koekemoer L, Coetzee M. Insecticide resistance in Anopheles arabiensis from Ethiopia. Afr Entomol. 2013;21(1): 89-94.

27. Walker K, Lynch M. Contributions of Anopheles larval control to malaria suppression in tropical Africa: review of achievements and potential. Med Vet Entomol. 2007;21(1):2-21.

28. Taye A, Hadis M, Adugna N, Tilahun D, Wirtz RA. Biting behavior and Plasmodium infection rates of Anopheles arabiensis from Sille, Ethiopia. Acta Trop. 2006;97(1):50-4.

29. Kenea O, Balkew M, Tekie H, Gebre-Michael T, Deressa W, Loha E, Lindtiørn B, Overgaard HJ. Human-biting activities of Anopheles species in southCentral Ethiopia. Parasit Vectors. 2016;9(1):527.

\section{Publisher's Note}

Springer Nature remains neutral with regard to jurisdictional claims in published maps and institutional affiliations.

Ready to submit your research? Choose BMC and benefit from:

- fast, convenient online submission

- thorough peer review by experienced researchers in your field

- rapid publication on acceptance

- support for research data, including large and complex data types

- gold Open Access which fosters wider collaboration and increased citations

- maximum visibility for your research: over $100 \mathrm{M}$ website views per year

At BMC, research is always in progress.

Learn more biomedcentral.com/submissions 